\title{
EDITORIAL
}

\section{Integrating biological measures into the design and evaluation of preventive interventions}

\author{
DANTE CICCHETTI AND MEGAN R. GUNNAR \\ University of Minnesota
}

The preeminent objective of the field of prevention science is to intervene in the course of development to reduce or eliminate the emergence of maladaptation and mental disorder, as well as to foster the recovery of function and to promote resilient adaptation in individuals at high risk for psychopathology (Cicchetti \& Hinshaw, 2002; Ialongo et al., 2006; Luthar \& Cicchetti, 2000). To fulfill this laudable goal, it is important that prevention scientists possess a complex, multilevel understanding of the course of normality to formulate an in-depth portrayal of how deviations in normal developmental processes can eventuate in maladaptation and psychopathology. The discipline of developmental psychopathology, with its major focus on the dialectic between normal and abnormal development, is uniquely poised to provide the theoretical foundation for prevention science (Cicchetti \& Toth, 1992, 2006a; Ialongo et al., 2006; Institute of Medicine, 1994).

\footnotetext{
Our work on this Editorial and Special Issue was partially supported by research grants from the National Institute of Drug Abuse (DA017741-01), the National Institute of Mental Health (MH54643, MH067792-01), and the Spunk Fund to Dante Cicchetti and a Senior Scientist Award (MH66208) and research grant (MH068857) from the National Institute of Mental Health to Megan R. Gunnar.

Address correspondence and reprint requests to: Dante Cicchetti, McKnight Presidential Chair of Child Psychology and Psychiatry, Institute of Child Development, University of Minnesota, 51 East River Road, Minneapolis, MN 55455; or Megan R. Gunnar, Regents Professor, Institute of Child Development, University of Minnesota, 51 East River Road, Minneapolis, MN 55455.
}

From a developmental psychopathology perspective, maladaptation and mental disorder are viewed as evolving from progressive liabilities in the organization of biological and psychological systems, resulting in the undermining of the individual's efforts to adapt effectively to stressful and adverse experiences (Cicchetti \& Tucker, 1994; Gunnar, 2003; Gunnar \& Vazquez, 2006). Prevention scientists are cognizant that there are multiple pathways to mental disorder and dysfunction, and that diverse causal processes likely operate for different individuals. Moreover, prevention researchers understand that a variety of maladaptive and adaptive outcomes will occur despite a common early liability or risk condition (Cicchetti \& Rogosch, 1996).

The dynamic interplay between risk and protective factors is conceived as influencing the developmental course through the impact it has on the quality of the organization of biological and psychological systems as the individual develops (Cicchetti \& Schneider-Rosen, 1986). Developmental psychopathology research emphasizes probabilistic, rather than deterministic, models of dysfunction (Gottlieb \& Willoughby, 2006; Rutter \& Sroufe, 2000). Moreover, various risk factors often co-occur, and the cumulative effects of multiple risk factors have been shown to be especially harmful to competent functioning, thereby promoting the development of psychopathology (Cicchetti \& Sroufe, 2000; Sameroff, 1989). Thus, it is important to examine causal models of psychopathology 
that elucidate the co-action of diverse risk factors at multiple levels of biological and psychological integration (Gottlieb \& Halpern, 2002; Masten, 2007).

In addition, attention to the protective factors that individuals possess and experience throughout development also is critical, especially because they may promote adaptation and resilience in their own right (Luthar, 2006; Masten, 2001). Moreover, some protective factors may be influential in preserving competent functioning in the context of specific risk factors (Cicchetti \& Sroufe, 2000). Research on biological, as well as psychological protective factors is vitally important for identifying processes that contribute to the development of either the recovery of function or resilient adaptation in the face of significant adversity (Cicchetti \& Curtis, 2007; Luthar, Cicchetti, \& Becker, 2000; Masten, 2001). Understanding the dynamic transactions between risk and protective factors plays a central role in building developmentally informed models of prevention. Through increasing the relative balance of protective processes over risk factors, the potential for righting the developmental course, attaining adaptive developmental pathways, and reducing the emergence of psychopathology may be achieved (Cicchetti \& Lynch, 1993).

The articles in this Special Issue of Development and Psychopathology stress the importance of integrating biological processes into the design and evaluation of preventive interventions. At present, the theories, experimental designs, and measurement batteries that undergird most randomized preventive trial interventions, especially those conducted with children and adolescents, have been dominated by the assessment of processes at the psychosocial and behavioral levels of analysis (Cicchetti \& Hinshaw, 2002; Ialongo et al., 2006).

Although predominantly nondevelopmental in nature, a number of preventive interventions conducted with adult patients who have mental disorders have begun to incorporate biological measurements into their evaluation of treatment efficacy (see, e.g., Baxter et al., 1992; Brody et al., 2001; Felmingham et al., 2007; Goldapple et al., 2004; Martin, Martin, Rai, Richardson, \& Royall, 2001; Paquette et al., 2003; Schwartz, Stoessel, Baxter, Martin, \& Phelps, 1996). In contrast, preventive interventions conducted with children and adolescents have paid minimal attention to neurobiological and physiological systems in their evaluations of treatment efficacy (for exceptions, see Bakermans-Kranenberg, van IJzendoorn, Pijlman, Mesman, \& Juffer, 2007; Dozier, Albus, Fisher, \& Sepulveda, 2002; Fisher, Gunnar, Dozier, Bruce, \& Pears, 2006).

There are at least two reasons for the dearth of attention to biological processes in the evaluation of preventive interventions with children and adolescents. Lack of attention may partly stem from a tradition in developmental psychology of measuring biological processes as indices of heritable, constitutional individual differences reflecting the neurobiological bases of temperament (e.g., Kagan, Reznick, \& Snidman, 1988; Schmidt \& Fox, 1998). This tradition encourages beliefs that biological processes are not malleable or are more refractory to positive change as a result of experience. Because there are bidirectional relations between different levels of psychological and biological organization, it is essential to recognize that experience also influences biology (Cicchetti \& Tucker, 1994; Eisenberg, 1995; Gunnar, 2003; Gunnar \& Quevedo, 2007). Evidence for neurobiological reorganization in response to alterations in the environment may be less apparent in normative populations where there likely is greater stability in supportive milieus, although even here there is increasing evidence that variations in the range of typical caregiving are associated over time with variations in neurobiological activity (e.g., Hane \& Fox, 2006). Nonetheless, investigations of individuals reared in extreme environments, such as those who have been maltreated or who have resided in an institution, as well as examinations of persons with mental disorder, should enable us to more clearly isolate the components of these diverse systems, thereby shedding light on the bidirectional effects of experience and neurobiology.

Although adversity and trauma are believed to exert deleterious effects on biological systems (DeBellis, 2001; Gunnar \& Vazquez, 2006), one of the major challenges in identifying biological targets for intervention is the nonexperimental nature of nearly all of our data on the biological impact of trauma and adversity in human 
development. Although we may observe differences in neurobiological activity between children who have and have not been exposed to traumatic events, we can neither randomly assign children to trauma nor do we have preexposure data that would allow assessment of trauma impact. Thus, we are left with correlates of trauma exposure that, instead of reflecting the impact of exposure to adversity or trauma, may potentially reflect preexisting differences that predispose children to heightened risk of exposure to adverse conditions or vulnerability in the face of such conditions. Of course, similar problems exist in the study of the psychological impact of such conditions in human development (see argument by Kaufman et al., 1998). We face a different but related problem in isolating neurobiological targets in studies of mental disorder in children. Specifically, although we may identify neurobiological correlates of different disorders, we do not know whether these reflect processes that impact core features of the disorder or not. Thus, it is not always clear whether changes in these biological correlates of the disorder over the course of an intervention will improve functions core to the disorder or not.

However, although these challenges may seem daunting, they provide a strong impetus for including biological measures in preventive interventions. Although random assignment to adversity and trauma are not possible, random assignment to intervention is. If biological systems recover in response to the intervention, then this provides support for arguments that the systems under study are sensitive to environmental input during development (Cicchetti \& Curtis, 2006). Furthermore, if randomized interventions alter neurobiological systems associated with disorders and it can be shown that they mediate changes in psychosocial and behavioral functioning, then this fosters a better understanding of the neurobiological bases of the disorder (Cicchetti, 2002). Moreover, preventive interventions may contribute to recovery or repair of biological sequelae in ways that have only begun to be understood. Improved comprehension of the neurobiological processes that increase risk of maladaptive development may also suggest novel targets for preventive intervention. Thus, it is important for prevention scientists to investigate the means by which changes in experience and psychological functioning resulting from preventive interventions may modify biological processes. Nevertheless, in the absence of theories about the nature of the effects that would be expected in a multilevel intervention, a multisystems approach to the design and evaluation of a randomized controlled trial (RCT) is not likely to provide clear answers (Gunnar, Fisher, \& The Early Experience, Stress, and Prevention Science Network, 2006).

From the integrative developmental psychopathology framework, RCTs can be conceptualized as veridical experiments in modifying the course of development. Therefore, these randomized preventive trials can be viewed as tests of theory and causal mechanisms, thereby proffering insights into the etiology and pathogenesis of maladaptation and disordered outcomes (Cicchetti \& Hinshaw, 2002; Howe, Reiss, \& Yuh, 2002; Ialongo et al., 2006; Kellam \& Rebok, 1992; Koretz, 1991). The incorporation of biological measures into the design and evaluation of these RCT preventive interventions will enable prevention scientists to grasp the development of maladaptation, psychopathology, and resilience in their full complexity. Methodologically sound prevention science that incorporates a theoretically informed and guided multiple levels of analysis perspective will provide a unique lens through which the processes responsible for the development, maintenance, and modification of both typical and atypical functional outcomes can be discerned (Cicchetti \& Hinshaw, 2002).

Translational research and multiple levels of analysis approaches have been increasingly implemented in the field of developmental psychopathology (Cicchetti \& Toth, 2006b; Gunnar \& Cicchetti, in press; Masten, 2007). Collaborative interdisciplinary preventive interventions between researchers and clinicians that take into account multiple levels of influence also will help to reduce the schisms that have long existed between science and practice. The incorporation of an interdisciplinary, multiple level perspective will enable prevention scientists to derive a more precise and comprehensive understanding of the mediators and moderators underlying successful and unsuccessful intervention outcomes.

Now that it has been demonstrated in animal studies that experience can exert impacts on the microstructure and biochemistry of the brain (e.g., Meaney \& Szyf, 2005), a vital role for 
continuing neural plasticity throughout epigenesis in contributing to the recovery from various forms of maladaptation and mental disorder may be suggested (Cicchetti \& Curtis, 2006). Thus, the time has come increasingly to conduct interventions that not only assess behavioral changes, but also investigate whether abnormal neurobiological structures, functions, and organizations are modifiable or are refractory to therapeutic alteration. There is growing evidence in the animal literature that efficacious interventions modify not only maladaptive behavior but also the cellular and physiological correlates of behavior (Kandel, 1979, 1999; Nelson, 2000; Nowakowski \& Bates, 1999). Successful preventive interventions may alter behavior and physiology through producing alterations in gene expression that create a new structural reorganization in the brain (Kandel, 1999). These data provide biologically plausible hypotheses about how effective interventions in children and adolescents function to impact development. Indeed, it seems highly likely that the efficacy of any preventive intervention ultimately depends on the ability of the nervous system, either at the cellular, metabolic, or anatomical level, to be modified by experience.

Neural plasticity has predominantly been thought of as reorganization within systems of the central nervous system (CNS), evidenced by changes in anatomy, neurochemistry, or metabolism. The neuroplastic changes that occur are often dramatic, and can include observable changes in the neural substrate that are translated into changes at the behavioral level. Such changes that are the hallmarks of plasticity can take place on one or more levels of analysis, including molecular, cellular, neurochemical, neuroanatomical, and at the level of brain systems (Cicchetti \& Curtis, 2006). The assumption underlying the concept of neural plasticity is that such modification is adaptive for the ongoing survival and optimal functioning of the organism (Hebb, 1949; Huttenlocher, 2002; Kempermann, 2005). Plasticity is an inherent property of the CNS (Kempermann, vanPraag, \& Gage, 2000), and it is thought that plasticity is one of the defining mechanisms of the evolutionary success of the human species (Hyman \& Nestler, 1993).

However, plasticity cuts both ways (Nelson $\&$ Carver, 1998). Neuroplastic adaptations that improve survival in some contexts may impair functioning in others or may come at a cost to the organism (McEwen, 2001). Plasticity is also the hallmark of the developing nervous system. Critical or sensitive periods exist during which plasticity is heightened in particular, neural systems, and following which these systems become less open to change. One important goal of preventive intervention work is to identify periods of development when a specific intervention may be more efficacious so that the intervention can be targeted to that period. One hope of preventive intervention work that includes measures of neural activity is to better identify sensitive periods for intervention (Zeanah et al., 2003).

In implementing studies of neurobiological functioning into work on preventive interventions, it is likely that researchers will need to grapple with many of the same challenges faced by researchers studying brain-behavior and physiology-behavior relations in typically developing children. One of the most challenging for the prevention researcher will be dealing with the low correlation, at times, between physiological and behavioral assessments. For measures of autonomic activity and hormones, low correlations with behavior may reflect, in part, the fact that the measure is biologically distant from the neurobiology of interest. That is, brain activity may be what the researcher is most interested in assessing and the biological measure is a reflection, albeit dim, of activity in the CNS. However, the problem of low association is also seen when the researcher collects more proximal measures of brain activity (e.g., event-related potentials, EEGs, and functional magnetic resonance imaging). Here the assumption is that the brain measures may be more sensitive than the behavioral measures or the behavioral measure reflects the operation of multiple systems, of which the neural activity under study composes only a part. In some instances, however, it may be that the biological measure may precede changes on the behavioral level (see, e.g., Fox, Henderson, Rubin, Calkins, \& Schmidt, 2001), or the neurobiological assessment may be more sensitive than the behavioral assessment (see, e.g., Bauer, Wiebe, Carver, Waters, \& Nelson, 2003). Given these challenges, we may need to be circumspect in heralding the clarity of insight 
that adding physiological and neurobiological measures into preventive intervention will provide. As in other studies of brain-behavior and physiology-behavior relations, we can anticipate a period of decreased clarity before we come to understand what these measures are telling us. In addition, in instances where the neurobiological changes may be sensitive to changes that contribute to processes supporting reorganization of behavior, we may find that preventive intervention studies with multiple assessments and longer time windows will be more informative than interventions that assess physiological and behavioral changes concurrently.

In summary, as the papers in this Special Issue attest, the prevention of maladaptation and mental disorder requires an in-depth knowledge of the dynamic relations among risk and protective factors and typical and atypical developmental processes. Clearly, the results of randomized prevention trials will be informative to practitioners. Nonetheless, it is essential that

\section{References}

Bakermans-Kranenberg, M. J., Van IJzendoorn, M. H., Pijlman, F. T. A., Mesman, J., \& Juffer, F. (2007). Experimental evidence for differential susceptibility: Dopamine D4 receptor polymorphism (DRD4 VNTR) moderates intervention effects on toddlers' externalizing behavior in randomized controlled trial. Developmental Psychology, 44, 293-300.

Bauer, P. J., Wiebe, S. A., Carver, L. J., Waters, J. M., \& Nelson, C. A. (2003). Developments in long-term explicit memory late in the first year of life: Behavioral and electrophysiological indices. Psychological Science, 14, 629-635.

Baxter, L. R., Schwartz, J. M., Bergman, K. S., Szuba, M. P., Guze, B. H., Mazziotta, J. C., et al. (1992). Caudate glucose metabolic rate changes with both drug and behavior therapy for obsessive-compulsive disorder. Archives of General Psychiatry, 58, 631-640.

Brody, A. L., Saxena, S., Stoessel, P., Gillies, L. A., Fairbanks, L. A., Alborzian, S., et al. (2001). Regional brain metabolic changes in patients with major depression treated with either paroxetine or interpersonal therapy: Preliminary findings. Archives of General Psychiatry, 58, 631-640.

Cicchetti, D. (2002). How a child builds a brain. In W. Hartup \& R. Weinberg (Eds.), Minnesota symposia on child psychology: Child psychology in retrospect and prospect (Vol. 30, pp. 23-71). Mahwah, NJ: Erlbaum.

Cicchetti, D., \& Curtis, W. J. (2006). The developing brain and neural plasticity: Implications for normality, psychopathology, and resilience. In D. Cicchetti \& D. Cohen (Eds.) Developmental psychopathology: Vol. 2. Developmental neuroscience (2nd ed., pp. 1-64). New York: Wiley.

Cicchetti, D., \& Curtis, W. J. (Eds.) (2007). A multi-level approach to resilience. Development and Psychopathology, 19, 627-955. prevention scientists conceptualize, design, and evaluate prevention trials in such a way that also enables their results to enhance our understanding of development and the pathways contributing to intervention efficacy at multiple levels of influence. Determining the multiple levels at which change is engendered through randomized prevention trials will provide more insights into the mechanisms of change, the extent to which neural plasticity may be promoted, and the interrelations between biological and psychological processes in maladaptation, psychopathology, and resilience (Cicchetti \& Curtis, 2006; Nelson, 2000). Furthermore, preventive interventions with the most in-depth empirical support, based on integrative multilevel theories of normality, psychopathology, and resilience, can be implemented in effectiveness trials in community or real-world settings to reach the broadest number of people and prevent, or alleviate, suffering from mental disorders (Toth, Nilsen, \& Manly, in press).

Cicchetti, D., \& Hinshaw, S. P. (Eds.). (2002). Prevention and intervention science: Contributions to developmental theory. Development and Psychopathology, 14, 667-981.

Cicchetti, D., \& Lynch, M. (1993). Toward an ecological/ transactional model of community violence and child maltreatment: Consequences for children's development. Psychiatry, 56, 96-118.

Cicchetti, D., \& Rogosch, F. A. (1996). Equifinality and multifinality in developmental psychopathology. Development and Psychopathology, 8, 597-600.

Cicchetti, D., \& Schneider-Rosen, K. (1986). An organizational approach to childhood depression. In M. Rutter C. Izard, \& P. Read (Eds.), Depression in young people, clinical and developmental perspectives (pp. 71-134). New York: Guilford Press.

Cicchetti, D., \& Sroufe, L. A. (2000). Editorial: The past as prologue to the future: The times, they've been a changin'. Development and Psychopathology, 12, 255-264.

Cicchetti, D., \& Toth, S. L. (1992). The role of developmental theory in prevention and intervention. Development and Psychopathology, 4, 489-493.

Cicchetti, D., \& Toth, S. L. (2006a). A developmental psychopathology persective on preventive interventions with high risk children and families. In A. Renninger \& I Sigel (Eds.), Handbook of child psychology (6th ed., pp. 497-547). New York: Wiley.

Cicchetti, D., \& Toth, S. L. (Eds.). (2006b). Translational research in developmental psychopathology. Development and Psychopathology, 18, 619-933.

Cicchetti, D., \& Tucker, D. (1994). Development and selfregulatory structures of the mind. Development and Psychopathology, 6, 533-549.

DeBellis, M. (2001). Developmental traumatology: The psychobiological development of maltreated children 
and its implications for research treatment and policy. Development and Psychopathology, 13, 539-564.

Dozier, M., Albus, K., Fisher, P. A., \& Sepulveda, S. (2002). Interventions for foster parents: Implications for developmental theory. Development and Psychopathology, 14, 843-860.

Eisenberg, L. (1995). The social construction of the human brain. American Journal of Psychiatry, 152, 1563-1575.

Felmingham, K., Kemp, A., Williams, L., Das, P., Hughes, G., Peduto, A., et al. (2007). Changes in anterior cingulate and amygdala after cognitive behavior therapy of posttraumatic stress disorder. Psychological Science, $18,127-129$.

Fisher, P. A., Gunnar, M. R., Dozier, M., Bruce, J., \& Pears, K. C. (2006). Effects of therapeutic interventions for foster children on behavioral problems, caregiver attachment, and stress regulatory neural systems. Annals of the New York Academy of Sciences, 1094, 215-225.

Fox, N. A., Henderson, H. A., Rubin, K. H., Calkins, S. D., \& Schmidt, L. A. (2001). Continuity and discontinuity of behavioral inhibition and exuberance: Psychophysiological and behavioral influences across the first four years of life. Child Development, 72, 1-21.

Goldapple, K., Segal, Z., Garson, C., Lau, M., Bieling, P., Kennedy, S., et al. (2004). Modulation of corticallimbic pathways in major depression. Archives of General Psychiatry, 61, 34-41.

Gottlieb, G., \& Halpern, C. T. (2002). A relational view of causality in normal and abnormal development. Development and Psychopathology, 14, 421-436.

Gottlieb, G., \& Willoughby, M. T. (2006). Probabilistic epigenesis of psychopathology. In D. Cicchetti \& D. Cohen (Eds.), Developmental psychopathology: Vol. 1. Theory and method (2nd ed., pp. 673-700). New York: Wiley.

Gunnar, M. R. (2003). Integrating neuroscience and psychological approaches in the study of early experiences. Annals of the New York Academy of Sciences, 1008, 238-247.

Gunnar, M. R., \& Cicchetti, D. (Eds.) (in press). Meeting the challenge of translational research in child development: The Minnesota symposia on child psychology (Vol. 35). New York: Wiley.

Gunnar, M. R., Fisher, P. A., \& The Early Experience Stress, and Prevention Science Network. (2006). Bringing basic research on early experience and stress neurobiology to bear on preventive intervention research on neglected and maltreated children. Development and Psychopathology, 18, 651-677.

Gunnar, M. R., \& Quevedo, K. (2007). The neurobiology of stress and development. Annual Review of Psychology, $58,145-173$.

Gunnar, M. R., \& Vazquez, D. M. (2006). Stress neurobiology and developmental psychopathology. In D. Cicchetti \& D. Cohen (Eds.), Developmental psychopathology: Vol. 2. Developmental neuroscience (2nd ed., pp. 533-577). New York: Wiley.

Hane, A. A., \& Fox, N. A. (2006). Ordinary variations in maternal caregiving influence human infants' stress reactivity. Psychological Science, 17, 550-556.

Hebb, D. O. (1949). The organization of behavior: A neuropsychological theory. New York: Wiley.

Howe, G. W., Reiss, D., \& Yuh, J. (2002). Can prevention trials test theories of etiology? Development and Psychopathology, 14, 673-694.

Huttenlocher, P. R. (2002). Neural plasticity: The effects of environment on the development of the cerebral cortex. Cambridge, MA: Harvard University Press.
Hyman, S. E., \& Nestler, E. J. (1993). The molecular foundations of psychiatry. Washington, DC: American Psychiatric Publishing.

Ialongo, N., Rogosch, F. A., Cicchetti, D., Toth, S. L., \& Neiderhiser, J. (2006). The importance of utilizing and translating basic research knowledge on normal and abnormal development into preventive interventions. In D. Cicchetti \& D. Cohen (Eds.), Developmental psychopathology: Vol. 1. Theory and method (2nd ed., pp. 968-1018). New York: Wiley.

Institute of Medicine. (1994). Reducing risks for mental disorders: Frontiers for preventive intervention research. Washington, DC: National Academy Press.

Kagan, J., Reznick, J. S., \& Snidman, N. (1988). Biological bases of childhood shyness. Science, 240, 167-171.

Kandel, E. R. (1979). Psychotherapy and the single synapse: The impact of psychiatric thought on neurobiologic research. New England Journal of Medicine, 301, 1028-1037.

Kandel, E. R. (1999). Biology and the future of psychoanalysis: A new intellectual framework for psychiatry revisited. American Journal of Psychiatry, 156, 505-524.

Kaufman, J., Birmaher, B., Brent, D. A., Dahl, R. E., Bridge, J., \& Ryan, N. D. (1998). Psychopathology in the relatives of depressed-abused children. Child Abuse and Neglect, 22, 171-181.

Kellam, S. G., \& Rebok, G. W. (1992). Building developmental and etiological theory through epidemiologically based preventive intervention trials. In J. McCord $\&$ R. E. Tremblay, (Eds.) Preventing antisocial behavior: Interventions from birth through adolescence ( $\mathrm{pp}$. 162-195). New York: Guilford Press.

Kempermann, G. (2005). Adult neurogenesis: Stem cells and neuronal development in the adult brain. Oxford: Oxford University Press.

Kempermann, G., van Praag, H., \& Gage, F. H. (2000). Activity-dependent regulation of neuronal plasticity and self repair. Progress in Brain Research, 127, 35-48.

Koretz, D. (1991). Prevention-centered science in mental health. American Journal of Community Psychology, $25,233-243$.

Luthar, S. S. (2006). Resilience in development: A synthesis of research across five decades. In D. Cicchetti \& D. Cohen, (Eds.), Developmental psychopathology: Vol. 3. Risk, disorder, and adaptation (2nd ed., pp. 739-795). New York: Wiley.

Luthar, S. S., \& Cicchetti, D. (2000). The construct of resilience: Implications for intervention and social policy. Development and Psychopathology, 12, 857-885.

Luthar, S. S., Cicchetti, D., \& Becker, B. (2000). The construct of resilience: A critical evaluation and guidelines for future work. Child Development, 71, 543-562.

Martin, S. D., Martin, E., Rai, S. S., Richardson, M. A., \& Royall, R. (2001). Brain blood flow changes in depressed patients treated with interpersonal psychotherapy or venlafaxine hydrochloride: Preliminary findings. Archives of General Psychiatry, 58, 641-648.

Masten, A. S. (2001). Ordinary magic: Resilience processes in development. American Psychologist, 56, 227-238.

Masten, A. S. (Ed.) (2007). Multilevel dynamics in developmental psychopathology: The Minnesota symposia on child psychology (Vol. 34, pp. 1-347). Mahwah, NJ: Erlbaum.

McEwen, B. (2001). Plasticity of the hippocampus: Adaptation to chronic stress and allostatic load. Annals of the New York Academy of Science, 933, 265-277.

Meaney, M. J., \& Szyf, M. (2005). Environmental programming of stress responses through DNA methylation: 
Life at the interface between a dynamic environment and a fixed genome. Dialogues in Clinical Neuroscience, 7, 103-123.

Nelson, C. A. (2000). The neurobiological bases of early intervention. In J. Shonkoff \& S. Meisels (Eds.), Handbook of early childhood intervention (2nd ed., pp. 204-227). New York: Cambridge University Press.

Nelson, C. A., \& Carver, L. J. (1998). The effects of stress and trauma on brain and memory: A view from developmental cognitive neuroscience. Development and Psychopathology, 10, 793-809.

Nowakowski, R., \& Bates, N. L. (1999). CNS development: An overview. Development and Psychopathology, 11, 395-417.

Paquette, V., Levesque, J., Mensour, B., Leroux, J. M., Beaudoin, G., Bourgouin, P., et al. (2003). Change the mind and you change the brain: Effects of cognitive-behavioral therapy on the neural correlates of spider phobia. NeuroImage, 18, 401-409.

Rutter, M., \& Sroufe, L. A. (2000). Developmental psychopathology: Concepts and challenges. Development and Psychopathology, 12, 265-296.
Sameroff, A. J. (1989). Models of developmental regulation: The environtype. In D. Cicchetti (Ed.), Rochester Symposium on Developmental Psychopathology: The emergence of a discipline (Vol. 1, pp. 41-68). Hillsdale, NJ: Erlbaum.

Schmidt, L., \& Fox, N. (1998). Fear-potentiated startle responses in temperamentally different human infants. Developmental Psychobiology, 32, 113-120.

Schwartz, J. M., Stoessel, P. W., Baxter, L. R., Martin, K. M., \& Phelps, M. E. (1996). Systematic changes in cerebral glucose metabolic rate after successful behavior modification treatment of obsessive-compulsive disorder. Archives of General Psychiatry, 53, 109-113.

Toth, S. L., Manly, J. T., \& Nilsen, W. (in press). From research to practice: Lessons learned. Journal of Applied Developmental Psychology.

Zeanah, C. H., Nelson, C. A., Fox, N. A., Smyke, A. T., Marshall, P. M., Parker, S. W., et al. (2003). Designing research to study the effects of institutionalization on brain and behavioral development: The Bucharest Early Intervention Project. Development and Psychopathology, 15, 885-907. 